\title{
A Perfect Absorber Based on Similar Fabry-Perot Four-Band in the Visible Range
}

\author{
Pinghui Wu ${ }^{1}$, Congfen Zhang ${ }^{2}$, Yijun Tang ${ }^{3}$, Bin Liu ${ }^{4}$ and Li Lv ${ }^{4, *}$ \\ 1 Research Center for Photonic Technology, Fujian Key Laboratory for Advanced Micro-nano Photonics \\ Technology and Devices \& Key Laboratory of Information Functional Material for Fujian Higher Education, \\ Quanzhou Normal University, Quanzhou 362000, China; phwu@zju.edu.cn \\ 2 College of Life Science and Engineering, Southwest University of Science and Technology, \\ Mianyang 621010, China; Zhang2017@swust.edu.cn \\ 3 College of Science, Zhejiang University of Technology, Hangzhou 310023, China; tyj1970@zjut.edu.cn \\ 4 School of Physics and Electric Engineering, Linyi University, Linyi 276000, China; liubin@lyu.edu.cn \\ * Correspondence: lvlilyu@163.com; Tel./Fax: +86-0539-7258280
}

Received: 12 February 2020; Accepted: 2 March 2020; Published: 8 March 2020

check for updates

\begin{abstract}
A simple metamaterial absorber is proposed to achieve near-perfect absorption in visible and near-infrared wavelengths. The absorber is composed of metal-dielectric-metal (MIM) three-layer structure. The materials of these three-layer structures are $\mathrm{Au}, \mathrm{SiO}_{2}$, and $\mathrm{Au}$. The top metal structure of the absorber is composed of hollow three-dimensional metal rings regularly arranged periodically. The results show that the high absorption efficiency at a specific wavelength is mainly due to the resonance of the Fabry-Perot effect (FP) in the intermediate layer of the dielectric medium, resulting in the resonance light being trapped in the middle layer, thus improving the absorption efficiency. The almost perfect multiband absorption, which is independent of polarization angle and insensitivity of incident angle, lends the absorber great application prospects for filtering and optoelectronics.
\end{abstract}

Keywords: broadband; metamaterial; perfect absorber; four-band absorption; COMSOL; surface plasmon polariton

\section{Introduction}

The dielectric constant of metal materials is less than zero in visible and infrared bands, which is contrary to the symbol of the dielectric constant. When micro and nanoscale metals and dielectrics are combined and interact with the electromagnetic field, they can produce different or even opposite optical phenomena in nature, such as negative refraction and slow light effect [1-5]. In recent years, it has been found that the combination of metal and dielectric materials can transform the incident electromagnetic wave into surface plasmon polariton (SPP), to enhance the light regulation ability of materials at the nanoscale [6]. Usually, when the light in free space travels to the air-metal interface, most of the energy is reflected, and some of it is converted into heat loss and absorbed by the material. Only a little power can penetrate the metal. However, with the appearance of metal-dielectric micro/nano structures, we can realize enhanced resonance absorption of electromagnetic waves in specific wavebands using surface iso-excimer resonance or other resonance effects. Among these structures, metal-dielectric-metal-based multilayer structures have natural magnetic resonance properties. They can respond to the incident magnetic field and generate antiparallel current on two metal surfaces. Thus, a local electromagnetic field is generated in the medium, which enhances the absorption of electromagnetic waves by the metal. On the macroscopic scale, a nanophotonic device with full absorption at a specific wavelength is formed. This device is an electromagnetic absorber [7].

When a material is used primarily to absorb certain bands of electromagnetic waves, we call it an electromagnetic absorber. Electromagnetic absorbers can be used in many different fields according 
to their absorption band, absorption capacity, absorption principle, and absorption spectrum [8-14]. For example, the Salisbury screen is mainly used in the military to reduce the reflection of radar detectors by canceling the interference of reflected microwaves by the reflection layer [15]. The same principle can be used in optical frequencies to design an anti-reflective film on a camera lens or glass. For another example, a pyramid-shaped structure can increase the number of reflections and scatter in the structure by matching the impedance of free space, thus increasing the absorption efficiency [16].

Since the concept of the perfect absorber was introduced in 2008, the research on superstructure electromagnetic material absorbers has shown exponential growth year by year [17-20]. From the initial microwave frequency band to terahertz [20,21], infrared [22,23], and visible frequency band [24-27], a large number of studies have been conducted, and absorption bandwidth also includes single-frequency absorption, dual-frequency absorption, multi-frequency absorption, and broadband absorption [28-33]. Compared with the traditional absorption materials, the advantage of the superstructure material absorber lies in the structure size, arrangement, and different materials selected to form the dual-frequency, multi-frequency, or dual-band absorber [34-36]. The structure size is small and the processing method is simple, which is conducive to the integration in the period surface [37-39]. The structure or quantity can be flexibly adjusted to achieve different absorption purposes. Due to the variety of absorbers, the absorbers have a different applicable wavelengths, bandwidths, structure characteristics, adjustable abilities, and absorption principles. In this paper, a multi-band metamaterial absorber in the visible light range is designed from the perspective of the absorption frequency band. By changing the structure size of the absorber and the metal structure on the surface, the absorber can achieve a broader tolerance range for polarization and incidence angle, which has potential for application in filtering and optoelectronics.

\section{Physical Design}

The metamaterial absorber we designed is shown in Figure 1. It has a metal-dielectric-metal multilayer structure from the bottom to the top. For the bottom layer of metal, we used gold as the material and as a metal mirror; the thickness was $300 \mathrm{~nm}$. The intermediate dielectric layer was $\mathrm{SiO}_{2}$. The depth of $\mathrm{SiO}_{2}$ was $100 \mathrm{~nm}$ and the relative dielectric constant was 2.13 [40,41]. The absorption layer was composed of a three-dimensional hollow metal ring arranged in a periodic structure. When constructing the geometric model, in order to find the best value, we used different values of 80-120 nm for the thickness of the node layer. We also changed the spacing between the hollow solid rings. At the same time, to study the relationship between the material of the absorption layer and the absorption, we chose different materials as the absorption layer for simulation. Its optimal structure size and parameters were: model width $\mathrm{w}_{1}=1000 \mathrm{~nm}$, three-dimensional circle inner diameter $\mathrm{r}_{1}=230 \mathrm{~nm}$, and three-dimensional circle inner diameter $r_{2}=130 \mathrm{~nm}$. The thickness of the reflective metal layer was $h_{1}=300 \mathrm{~nm}$. The thickness of the dielectric layer was $h_{2}=100 \mathrm{~nm}$. The thickness of the absorption layer gold was $h_{3}=130 \mathrm{~nm}$ and the ring spacing of the absorption layer was $\mathrm{d}=40 \mathrm{~nm}$. We used the Drude model to set the detailed parameters of $\mathrm{Au}$ and commercial software COMSOL to simulate the structure [42].

(a)

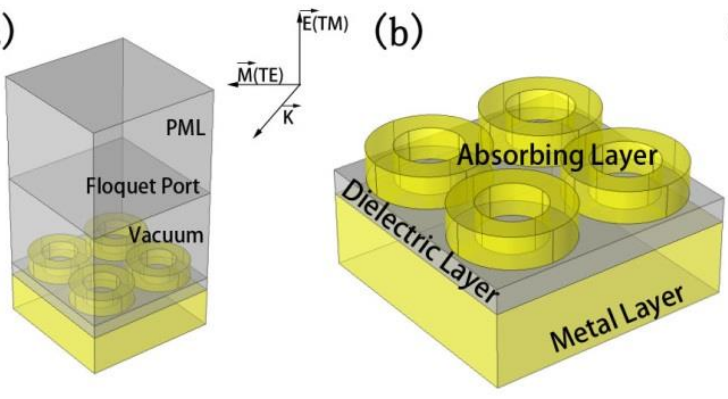

(c)

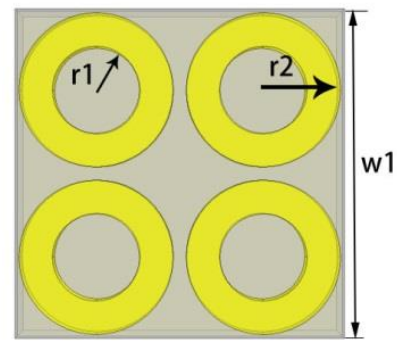

Figure 1. Basic absorber schematic: (a) a periodic unit structure of the absorber, (b) schematic diagram of the components of the absorber, and (c) top view of the absorber. 
The fabrication method of the structure is simple in practical application. First, an Au array was prepared by electron beam evaporation. Then, high-resolution electron beam (EB) lithography and reactive ion coating method were used to regulate the viscosity, and the rotation speed of the coating method was used to regulate the viscosity and rotation speed of the coating material to accurately control the thickness of $\mathrm{SiO}_{2}$ layer. Finally, the gold array was prepared again using electron beam evaporation and ultraviolet lithography $[43,44]$.

During the simulation with COMSOL, by setting the boundary conditions and port types of the metamaterial absorber, the metamaterial absorber we designed can become a periodic array structure. In a simulation, the absorption of the metamaterial absorber can be expressed as $\mathrm{A}(\omega)=1-\mathrm{R}(\omega)-\mathrm{T}(\omega)$ [45-49]. $\mathrm{A}(\omega)$ is the absorptivity, $\mathrm{R}(\omega)$ is reflectivity and $\mathrm{T}(\omega)$ is transmittance. However, the incorporation of the metamaterial absorber can be rewritten as $A(\omega)=1-R(\omega)$, if the transmitted light is zero due to the presence of the metal mirror in the absorber. In addition, although the MIM (metal-dielectric-metal) structure has three layers, generally only a two-layer model can represent the three-layer MIM structure. Because the MIM structure at the bottom of the metal layer is often add after, it can simulate semi-infinite metal substrate, leading to almost zero transmission energy. The relative permeability is 1 , the metal-dielectric substrate (top half infinite) relative dielectric constant is $n_{1}$, which a negative real part, and the imaginary part is zero. The dielectric layer in the middle of the relative dielectric constant is $n_{2}$, with a positive real part, and the imaginary part is not null. Therefore, when the light in the absorber is incident, it will have a resonance coupling effect with the dielectric layer and the absorption layer, causing the light to be absorbed by the absorber. The absorption intensity is also related to the relative permittivity of the metal and the dielectric layer, and the absorption can be adjusted through the relative permittivity.

\section{Results and Discussions}

In the absorber, the top structure corresponds to a Fabry-Perot cavity. The absorption principle is based on interference enhancement and interference reduction at the interface. The electromagnetic field is reflected and transmitted multiple times on the interface in the metamaterial, and finally superimposed multiple times in the incident plane. If the superimposed result is zero or small, it means that the electromagnetic field has formed interference cancellation in the incident surface after passing through the metamaterial, so there is no reflection or the reflection is very small. Because the back is metal, the electromagnetic field cannot pass through, so the electromagnetic field is completely absorbed. Hence, the electromagnetic field is totally absorbed, which explains the absorption principle of the metamaterials. Therefore, the resonant frequency and absorption efficiency of the absorber can be changed by changing the geometric and structural parameters of the absorber.

\section{A. The study of different polarization patterns}

Figure 2 shows the absorption curve of the absorber under the polarization of TE (transverse electric, the electric field is parallel to the $\mathrm{Y}$ direction) and TM (transverse magnetic, the electric field is parallel to the $X$ direction). By observing Figure 2, we can find that the absorber has four resonance absorption modes, among which there are three resonance absorption peaks at 459,614 , and $630 \mathrm{THz}$, with the absorption of $96.2 \%, 99.9 \%$, and 95.8\%, respectively. A broadband absorption was also produced in the 523-592.5 THz range with more than $90 \%$ absorption, and broadband center absorption reached $99.3 \%$. In addition, by comparing Figure $2 a$ with Figure $2 b$, we see that the position and intensity of resonance absorption of the absorber are approximately the same, whether in TE mode or TM mode. This is because the absorption layer of the absorber is arranged periodically and regularly. Regardless of incidence from the $X$ direction or event from the $Y$ direction, it has excellent light absorption characteristics. To further study the multipeak absorption of the absorber, we drew the electric field current scanning diagram at different peak times, as shown in Figure 3. 
(a)

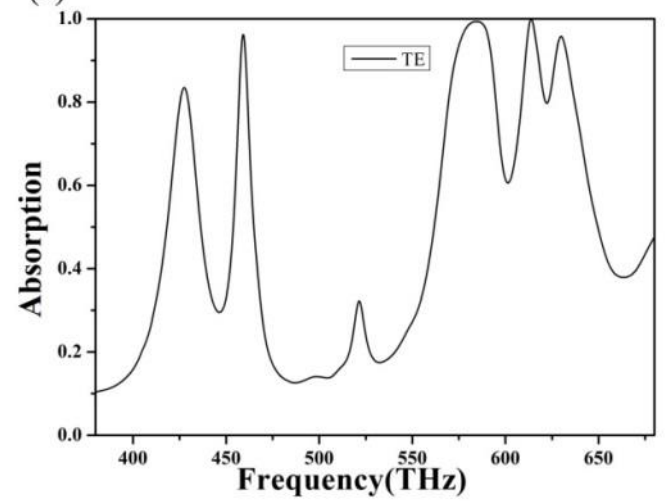

(b)

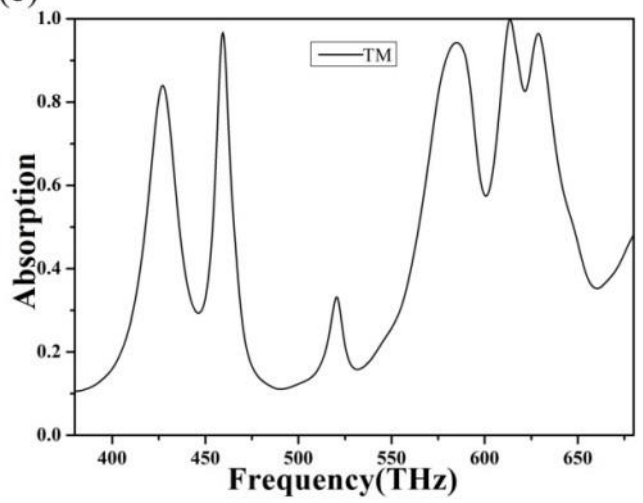

Figure 2. (a) The absorption curve under TE polarization, and (b) the absorption curve under TM polarization.

(a)

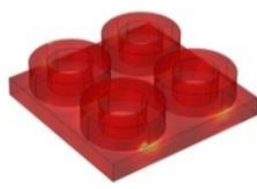

(b)

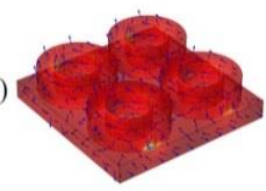

$459 \mathrm{THz}$
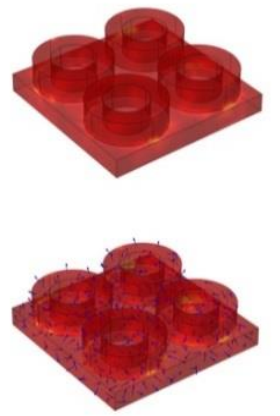

$584.5 \mathrm{THz}$
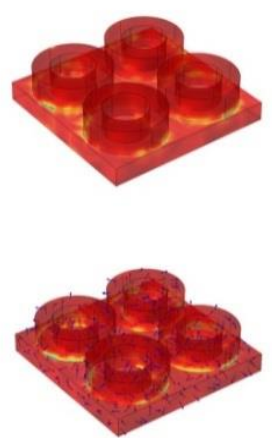

$614 \mathrm{THz}$
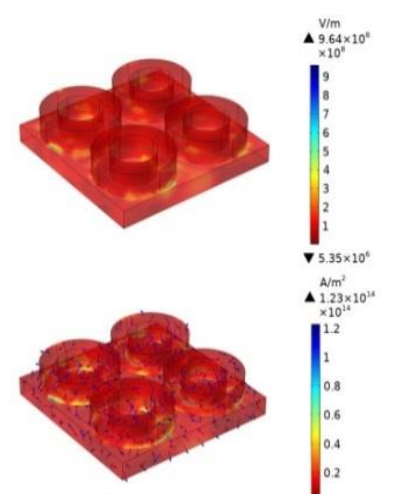

$630 \mathrm{THz}$

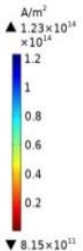

Figure 3. (a,b) The electric field and current distribution of the absorber in four resonant modes: 459, $584.5,614$, and $630 \mathrm{THz}$.

Figure 3 shows the electric field current diagram of the absorber. We show the electric field and surface current density of the absorber in different resonance modes in the figure, and draw the direction of the electromagnetic field. In Figure 3, by observing the electric fields at 459 and $584.5 \mathrm{THz}$, only a small part of the layer has a coupling resonance with the node layer. At 630 and $614 \mathrm{THz}$, all absorbing and dielectric layers showed resonance coupling. Electromagnetic field energy was a local area in the middle of the dielectric layer. We drew the electric displacement vector of cloth as well as the direction, which clearly shows the lower level metal surface had opposite surface currents, formed in the middle of the $\mathrm{SiO}_{2}$ circuit, and a negative magnetic response in the positive direction. However, in TM mode, different polarization states were caused due to different incident directions, thus slightly deviating the absorption curve.

\section{B. Study on absorption of different structural parameters}

First, we studied the effect of the absorber on the absorption when the thickness of the dielectric layer is changed. In this study, we used a controlled variable approach to ensure that the content under review was not affected by other parameters of the absorber. The thickness of the dielectric layer was taken from $\mathrm{nm}$ to $120 \mathrm{~nm}$ with a step length of $10 \mathrm{~nm}$, and the scanning absorption image in the visible band was drawn, as shown in Figure 4. By looking at the absorption lines, we can see that the absorption summit moves toward the lower frequency side as the dielectric layer thickness increases. Redshift can be explained by the propagation phase, where $\alpha$ is the propagation phase, which is caused by:

$$
\alpha=\frac{4 \mathrm{~h} \sqrt{\varepsilon_{\mathrm{r}}-\sin ^{2} \theta}}{\lambda},
$$


where $h$ is the thickness of the dielectric layer, $\epsilon$ is the real part of the effective dielectric constant of the absorber, $\theta$ is the incident angle, and $\lambda$ is the terahertz wavelength. Since $\epsilon$ and $\theta$ are attached, if $\alpha$ is considered a fixed value, then $h / \lambda$ is also fixed. This means that $h$ is inversely proportional. Therefore, as the thickness of the dielectric layer increases, the center frequency will shift to the lower frequency. We can also find that the four absorption peaks, on the whole, show a trend of first increasing and then decreasing [50-52]. At the dielectric layer thickness of $100 \mathrm{~nm}$, high peak values can be guaranteed at the four resonance positions. Therefore, at this time, the surface impedance of the absorber is perfectly matched with the free space impedance, achieving the best absorption effect.

(a)

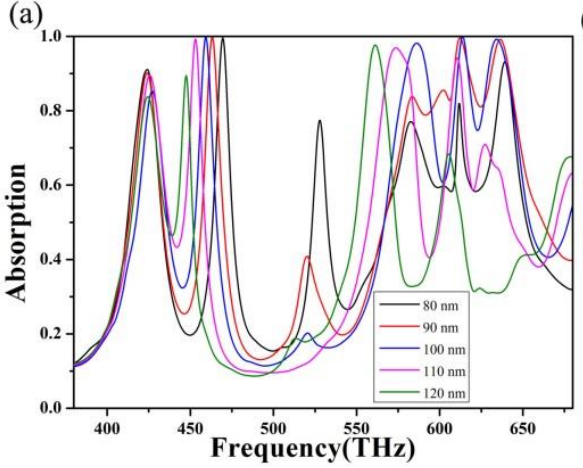

(b)

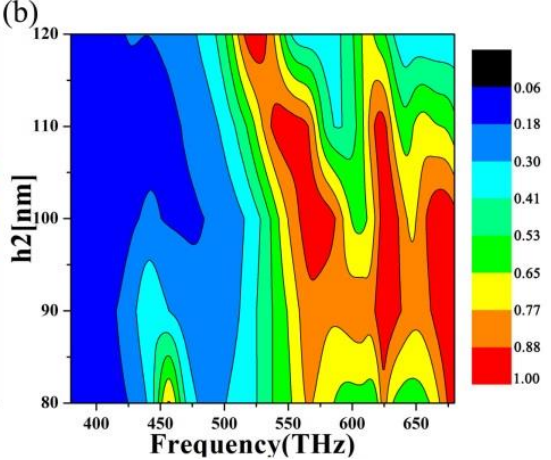

Figure 4. (a) Absorption curve and (b) absorption images of scanning dielectric layer thickness $(80-120 \mathrm{~nm})$ at 380-680 THz.

Secondly, we studied the effect of changing the spacing of the four hollow solid rings in the absorption layer of the absorber by using the control variable method. In this study, the spacing of the three-dimensional hollow ring was evaluated from 30 to $50 \mathrm{~nm}$ with a step length of $5 \mathrm{~nm}$, and the scanning absorption image in the visible light band was drawn, as shown in Figure 5. By observing Figure 5, we can find that when the spacing changes, the position of the absorption peak will not change, but the intensity will vary. This is because when the distance between the absorption layer changes, the resonance intensity between the absorption layer and the dielectric layer below the absorber changes $[53,54]$. Besides, the height of the absorption layer determines the position of the absorption peak.
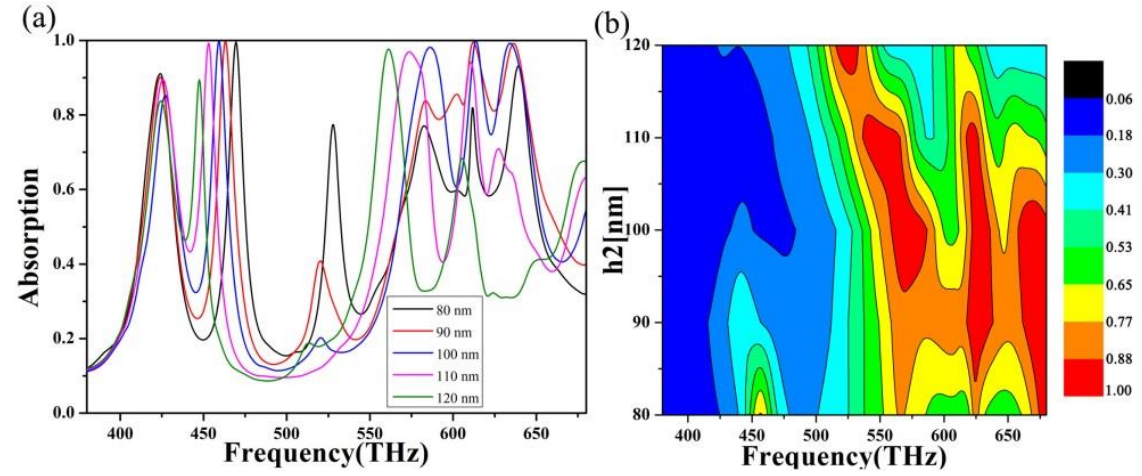

Figure 5. The absorption images of the three-dimensional ring pitch $(30-50 \mathrm{~nm})$ of the absorption layer when the frequency is changed from $380-680 \mathrm{THz}(\mathbf{a}, \mathbf{b})$.

In addition, considering the practical application of the absorption layer, we simulated the absorption of the absorber at a large angle and small angle, as shown in Figure 6. It can be seen from the figure that when the perspective of the absorber changes in a small area, the absorption change of the absorber is small. When the angle of incidence is large, the overall absorption of the absorber is significantly reduced, but there are still perfect absorption peaks. When the incident angle is zero, 
the absorption effect is better, there are three absorption peaks, and the existing absorption bandwidth is also extensive. As the aspect of incidence changes, the position of the absorption peak and the intensity of the absorption changes. When the incident angle of the absorber increases, the absorption rate decreases due to the increase in light reflection under high oblique incidence. In addition, when the incident angle increases, the magnetic dipole oscillation of the entire vibration absorber is effectively excited so that the strong absorption characteristics are maintained at a large angle, which is also the reason why there is a perfect absorption peak at a large angle. In general, the absorber can operate within and maintain a very high ideal absorption regardless of whether the incident angle is small or large.
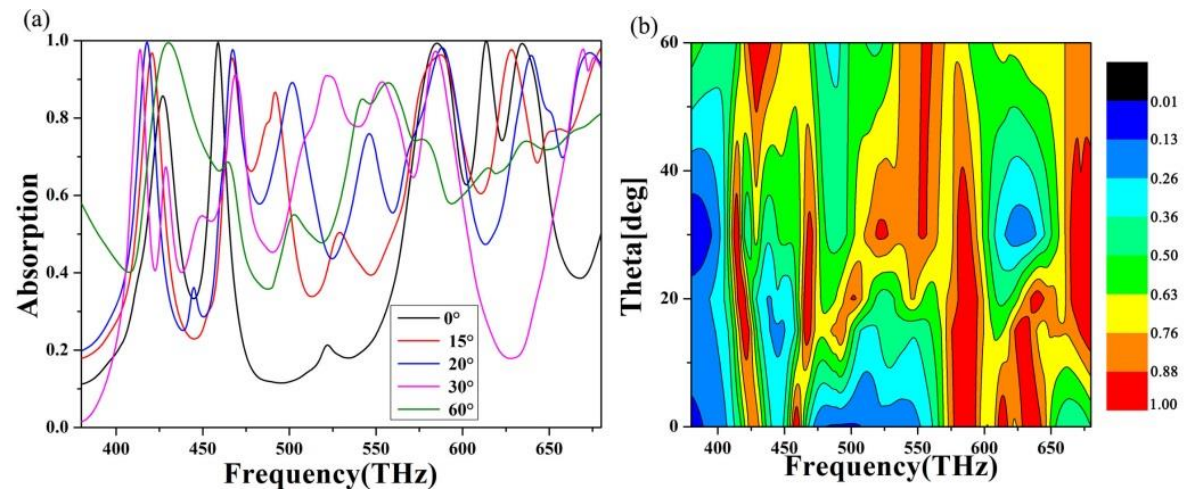

Figure 6. The absorption images at scanning incidence angle $\left(0^{\circ}-60^{\circ}\right)$ at $380-680 \mathrm{THz}(\mathbf{a}, \mathbf{b})$.

\section{Effects of different material properties on absorber absorption}

As different metal materials correspond to different plasma and collision frequencies, the absorption performance of the absorber will also alter. Therefore, we selected four common metal materials, namely gold, silver, aluminum, and copper, to simulate the absorption performance of the absorber.

The absorption properties of gold were studied in detail in the previous part of this paper, so we will not elaborate this part in detail. As the material properties of gold and silver are similar, we first selected Ag as the metal mirror of the absorber and the top absorption structure layer $[55,56]$. The absorption curve is shown in Figure $7 \mathrm{~b}$. We can observe through observation that when silver is used as the material of the absorption layer, there are only two resonance absorption peaks with an absorption rate of more than $90 \%$. Besides, the absorption curve wave is relatively apparent. There are a lot of low absorption peaks due to the incident light irradiation on the silver and the following $\mathrm{SiO}_{2}$. Different frequencies of light will make the two parts produce resonance a coupling effect. Also, the absorption layer can absorb different frequencies of incident light, which caused some messy small peaks to appear. At the same time, the positions of the two stiff coupling peaks are changed due to different material properties.

Considering that the price of gold and silver is generally higher and the actual processing cost is higher, we think that $\mathrm{Al}$ and $\mathrm{Cu}$, given their lower prices, should be used as the material for the metal layer of the absorber. We changed the absorption layer of the absorber and the content at the bottom into aluminum; the resulting absorption curve is shown in Figure 7c. Through observation, we found that when Al was used as the material of absorption layer, the absorption curve changed considerably compared with that of gold, the position of resonance absorption peak shifted, and the intensity of absorption peak also significantly improved. Broad-spectrum absorption occurs in the range of 644 and $670 \mathrm{THz}[57,58]$. This is because the plasma frequency of $\mathrm{Al}$ is higher than that of gold, which leads to a change in the resonant coupling mode between the absorption layer and the dielectric layer, resulting in wide-spectrum absorption. In addition, the position of resonance absorption peak changed due to the change in plasma frequency.

Finally, the most common metal material $\mathrm{Cu}$ was considered and simulated, as shown in Figure $7 \mathrm{~d}$. Through observation, we found that the absorption curve of copper was almost completely coincident 
with that of gold because the plasma frequency and collision frequency of copper are very close to that of gold. Therefore, when visible light shone on it, the resonance coupling mode was almost the same. Compared with copper, metallography has a broadband absorption in the absorption curve, which is more favorable for practical applications such as filter detection.
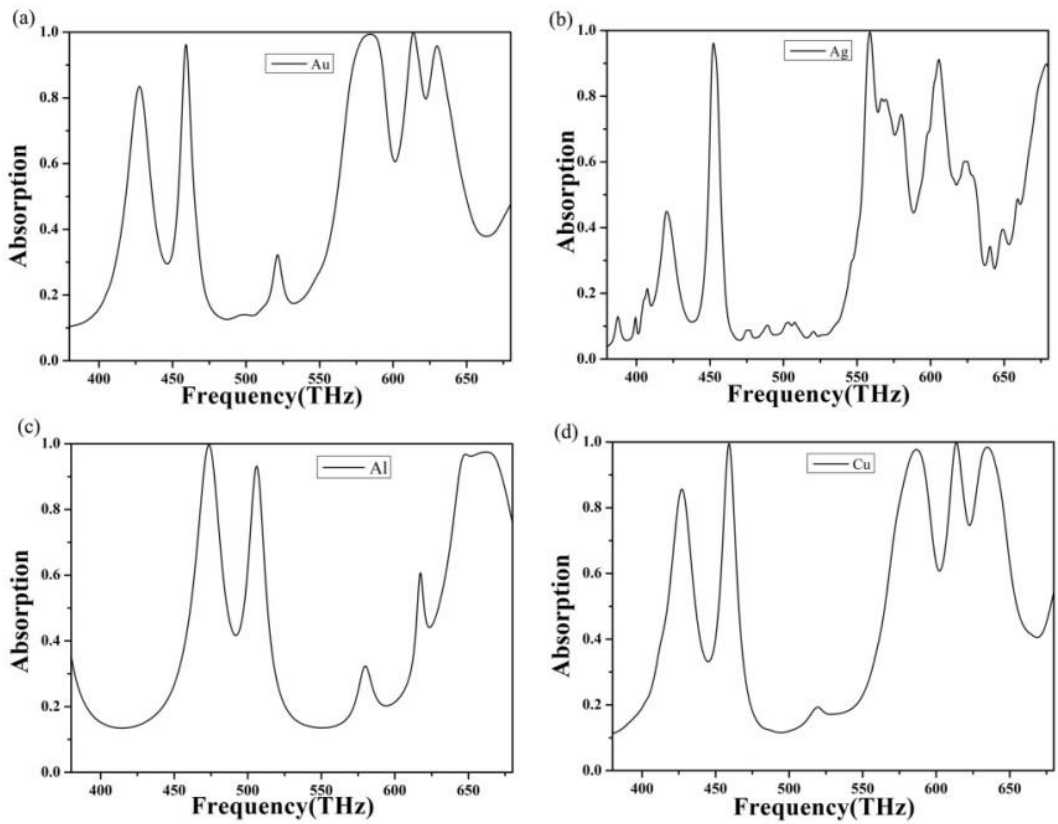

Figure 7. Change in the absorption spectrum of the absorber metamaterial. (a) The absorption curve when the material is gold, (b) the absorption curve when the material is silver, (c) the absorption curve is when the material is aluminum, and (d) the absorption curve when the material is copper.

\section{Conclusions}

In conclusion, we designed a simple visible metamaterial perfect absorber with three classic absorption peaks and small broadband. The intensity of absorption peaks and broadband intensity can reach above $97.8 \%$ on average. We studied the absorption curves of the absorber under different polarization conditions and found that the absorber has polarization insensitivity. We also studied the polarization angle, incident angle, and other parameters of the absorber in detail, indicating that the absorber can work stably under different polarizations and incident angles. In addition, the absorption characteristics of different materials of the absorber were studied, and we was found that the absorber can maintain good absorption characteristics when the material of the absorption layer is Au. The above characteristics make the absorber have potential for application in the fields of filtering and photoelectricity.

Author Contributions: P.W., C.Z., Y.T., B.L., and L.L. conceived and designed simulation; P.W. performed the simulation; P.W., C.Z., Y.T., B.L., and L.L. analyzed the data; P.W. and C.Z. contributed reagents/materials/analysis tools; P.W. wrote the paper. All authors have read and agreed to the published version of the manuscript.

Funding: This work was supported by the National Natural Science Foundation of China $(11704223,11747099)$, the Natural Science Foundation of Fujian Province (2018J05008, JZ160459), the Ph.D. Research Startup Foundation of Quanzhou Normal University (G16057, H19034), and the Distinguished Young Scholars Program of Fujian Province (C18032).

Conflicts of Interest: The authors declare no conflict of interest. 


\section{References}

1. Lezec, H.J.; Dionne, J.A.; Atwater, H.A. Negative Refraction at Visible Frequencies. Science 2007, 316, 430-432. [CrossRef] [PubMed]

2. Shin, H.; Fan, S. All-Angle Negative Refraction for Surface Plasmon Waves Using a Metal-Dielectric-Metal Structure. Phys. Rev. Lett. 2006, 96, 073907. [CrossRef] [PubMed]

3. Wu, P.H.; Chen, Z.Q.; Jile, H.; Zhang, C.F.; Xu, D.Y.; Lv, L. An Infrared Perfect Absorber Based on Metal-Dielectric-Metal Multi-layer Films with Nanocircle Holes Arrays. Results Phys. 2020, 16, 102952. [CrossRef]

4. Wang, Y.Y.; Chen, Z.Q.; Xu, D.Y.; Yi, Z.; Chen, X.F.; Chen, J.; Tang, Y.J.; Wu, P.H.; Li, G.F.; Yi, Y.G. Triple-band perfect metamaterial absorber with good operating angle polarization tolerance based on split ring arrays. Results Phys. 2020, 16, 102951. [CrossRef]

5. Wang, Y.Y.; Qin, F.; Yi, Z.; Chen, X.F.; Zhou, Z.G.; Yang, H.; Liao, X.; Tang, Y.J.; Yao, W.T.; Yi, Y.G. Effect of slit width on surface plasmon resonance. Results Phys. 2019, 15, 102711. [CrossRef]

6. $\quad$ Liang, C.P.; Yi, Z.; Chen, X.F.; Tang, Y.J.; Yi, Y.; Zhou, Z.G.; Wu, X.G.; Huang, Z.; Yi, Y.G.; Zhang, G.F. Dual-band infrared perfect absorber based on a Ag-dielectric-Ag multilayer films with nanoring grooves arrays. Plasmonics 2020, 15, 93-100. [CrossRef]

7. La Spada, L.; Vegni, L. Metamaterial-based wideband electromagnetic wave absorber. Opt. Express 2016, 24, 5763. [CrossRef]

8. Yan, Y.X.; Yang, H.; Yi, Z.; Xian, T.; Li, R.S.; Wang, X.X. Construction of $\mathrm{Ag}_{2} \mathrm{~S}_{\mathrm{CaTiO}}$ heterojunction photocatalysts for enhanced photocatalytic degradation of dyes. Desalin. Water Treat. 2019, 170, 349-360. [CrossRef]

9. Yan, Y.X.; Yang, H.; Yi, Z.; Wang, X.X.; Li, R.S.; Xian, T. Evolution of Bi nanowires from BiOBr nanoplates through a $\mathrm{NaBH}_{4}$ reduction method with enhanced photodegradation performance. Environ. Eng. Sci. 2020, 37, 64-77. [CrossRef]

10. Wang, Y.P.; Jiang, F.C.; Chen, J.F.; Sun, X.F.; Xian, T.; Yang, H. In situ construction of CNT/CuS hybrids and their application in photodegradation for removing organic dyes. Nanomaterials 2020, 10, 178. [CrossRef]

11. Yan, Y.X.; Yang, H.; Yi, Z.; Li, R.S.; Xian, T. Design of ternary $\mathrm{CaTiO}_{3} / g-\mathrm{C}_{3} \mathrm{~N}_{4} / \mathrm{AgBr}$ Z-scheme heterostructured photocatalysts and their application for dye photodegradation. Solid State Sci. 2020, 100, 106102. [CrossRef]

12. Wang, Y.P.; Yang, H.; Sun, X.F.; Zhang, H.M.; Xian, T. Preparation and photocatalytic application of ternary $\mathrm{n}-\mathrm{BaTiO}_{3} / \mathrm{Ag} / \mathrm{p}-\mathrm{AgBr}$ heterostructured photocatalysts for dye degradation. Mater. Res. Bull. 2020, 124, 110754. [CrossRef]

13. Liu, Z.; Liu, G.; Fu, G.; Liu, X.; Wang, Y. Multi-band light perfect absorption by a metal layer-coupled dielectric metamaterial. Opt. Express 2016, 24, 5020-5025. [CrossRef] [PubMed]

14. Vafapour, Z. Slow light modulator using semiconductor metamaterial//Integrated Optics: Devices, Materials, and Technologies XXII. Int. Soc. Opt. Photonics 2018, 10535, 105352A.

15. Fante, R.L.; McCormack, M.T. Reflection properties of the Salisbury screen. IEEE Trans. Antennas Propag. 1988, 36, 1443-1454. [CrossRef]

16. Abedini Dereshgi, S.; Ghobadi, A.; Hajian, H.; Butun, B.; Ozbay, E. Ultra-Broadband, Lithography-Free, and Large-Scale Compatible Perfect Absorbers: The Optimum Choice of Metal layers in Metal-Insulator Multilayer Stacks. Sci. Rep. 2017, 7, 14872. [CrossRef]

17. Ghafari, S.; Forouzeshfard, M.R.; Vafapour, Z. Thermo Optical Switching and Sensing Applications of an Infrared Metamaterial. IEEE Sens. J. 2020, 20, 3235-3241. [CrossRef]

18. Arju, N.; Ma, T.; Khanikaev, A.; Purtseladze, D.; Shvets, G. Optical Realization of Double-Continuum Fano Interference and Coherent Control in Plasmonic Metasurfaces. Phys. Rev. Lett. 2015, 114, 237403. [CrossRef]

19. Guan, S.T.; Yang, H.; Sun, X.F.; Xian, T. Preparation and promising application of novel $\mathrm{LaFeO}_{3} / \mathrm{BiOBr}$ heterojunction photocatalysts for photocatalytic and photo-Fenton removal of dyes. Opt. Mater. 2020, 100, 109644. [CrossRef]

20. Yu, P.Q.; Chen, X.F.; Yi, Z.; Tang, Y.J.; Yang, H.; Zhou, Z.G.; Duan, T.; Cheng, S.B.; Zhang, J.G.; Yi, Y.G. A numerical research of wideband solar absorber based on refractory metal from visible to near infrared. Opt. Mater. 2019, 97, 109400. [CrossRef] 
21. Cen, C.L.; Zhang, Y.B.; Chen, X.F.; Yang, H.; Yi, Z.; Yao, W.T.; Tang, Y.J.; Yi, Y.G.; Wang, J.Q.; Wu, P.H. A dual-band metamaterial absorber for graphene surface plasmon resonance at terahertz frequency. Physica $E$ 2020, 117, 113840. [CrossRef]

22. Wu, P.H.; Chen, Z.Q.; Xu, D.Y.; Zhang, C.F.; Jian, R.H. A Narrow Dual-Band Monolayer Unpatterned Graphene-Based Perfect Absorber with Critical Coupling in the Near Infrared. Micromachines 2020, 11, 58. [CrossRef] [PubMed]

23. Ogawa, S.; Kimata, M. Metal-Insulator-Metal-Based Plasmonic Metamaterial Absorbers at Visible and Infrared Wavelengths: A Review. Materials 2018, 11, 458. [CrossRef] [PubMed]

24. Cen, C.L.; Chen, Z.Q.; Xu, D.Y.; Jiang, L.Y.; Chen, X.F.; Yi, Z.; Wu, P.H.; Li, G.F.; Yi, Y.G. High quality factor, high sensitivity metamaterial graphene-perfect absorber based on critical coupling theory and impedance matching. Nanomaterials 2020, 10, 95. [CrossRef] [PubMed]

25. Vafapour, Z. Polarization-independent perfect optical metamaterial absorber as a glucose sensor in Food Industry applications. IEEE Trans. NanoBiosci. 2019, 18, 622-627. [CrossRef] [PubMed]

26. Qin, F.; Chen, Z.Q.; Chen, X.F.; Yi, Z.; Yao, W.T.; Duan, T.; Wu, P.H.; Yang, H.; Li, G.F.; Yi, Y.G. A Tunable Triple-Band Near-Infrared Metamaterial Absorber Based on Au Nano-Cuboids Array. Nanomaterials 2020, 10, 207. [CrossRef] [PubMed]

27. Li, J.K.; Chen, Z.Q.; Yang, H.; Yi, Z.; Chen, X.F.; Yao, W.T.; Duan, T.; Wu, P.H.; Li, G.F.; Yi, Y.G. Tunable Broadband Solar Energy Absorber Based on Monolayer Transition Metal Dichalcogenides Materials Using Au Nanocubes. Nanomaterials 2020, 10, 257. [CrossRef]

28. Islam, M.S.; Sultana, J.; Biabanifard, M.; Vafapour, Z.; Nine, M.J.; Dinovitser, A.; Cordeiro, C.M.B.; Ng, B.W.-H.; Abbott, D. Tunable localized surface plasmon graphene metasurface for multiband superabsorption and terahertz sensing. Carbon 2020, 158, 559-567. [CrossRef]

29. Li, J.K.; Chen, X.F.; Yi, Z.; Yang, H.; Tang, Y.J.; Yi, Y.; Yao, W.T.; Wang, J.Q.; Yi, Y.G. Broadband solar energy absorber based on monolayer molybdenum disulfide using tungsten elliptical arrays. Mater. Today Energy 2020, 16, 100390. [CrossRef]

30. Yang, M.M.; Dai, J.Y.; He, M.Y.; Duan, T.; Yao, W.T. Biomass-derived carbon from Ganoderma lucidum spore as a promising anode material for rapid potassium-ion storage. J. Colloid Interface Sci. 2020, 567, 256-263. [CrossRef]

31. Kou, Z.Y.; Miao, C.; Mei, P.; Zhang, Y.; Yan, X.M.; Jiang, Y.; Xiao, W. Enhancing the cycling stability of all-solid-state lithium-ion batteries assembled with $\mathrm{Li}_{1.3} \mathrm{Al}_{0.3} \mathrm{Ti}_{1.7}\left(\mathrm{PO}_{4}\right)_{3}$ solid electrolytes prepared from precursor solutions with appropriate $\mathrm{pH}$ values. Ceram. Int. 2020. [CrossRef]

32. Zhang, F.; Wang, Q.; Zhou, T.; Xiong, Y.J.; Wen, Y.Q.; Jiang, C.; Wang, Y.; Du, Z.J.; Abrahams, I.; Wang, L.Z.; et al. A multi-band binary radar absorbing metamaterial based on a 3D low-permittivity all-dielectric structure. J. Alloy Compd. 2020, 814, 152300. [CrossRef]

33. Pan, M.Y.; Huang, Y.; Li, Q.; Luo, H.; Zhu, H.Z.; Kaur, S.; Qiu, M. Multi-band middle-infrared-compatible camouflage with thermal management via simple photonic structures. Nano Energy 2020, 69, 104449. [CrossRef]

34. AL-Rjoub, A.; Rebouta, L.; Costa, P.; Barradas, N.P.; Alves, E.; Ferreira, P.J.; Pischow, K. A design of selective solar absorber for high temperature applications. Sol. Energy 2018, 172, 177-183. [CrossRef]

35. Lv, Y.R.; Li, Y.H.; Han, C.; Chen, J.F.; He, Z.X.; Zhu, J.; Dai, L.; Meng, W.; Wang, L. Application of porous biomass carbon materials in vanadium redox flow battery. J. Colloid Interface Sci. 2020, 566, 434-443. [CrossRef] [PubMed]

36. Zhang, W.B.; Xiao, Y. Mechanism of Electrocatalytically Active Precious Metal (Ni, Pd, Pt, and Ru) Complexes in the Graphene Basal Plane for ORR Applications in Novel Fuel Cells. Energy Fuels 2020, 34, 2425-2434. [CrossRef]

37. Song, S.; Ma, X.; Pu, M.; Li, X.; Guo, Y.; Gao, P.; Luo, X. Tailoring active color rendering and multiband photodetection in a vanadium-dioxide-based metamaterial absorber. Photonics Res. 2018, 6, 492. [CrossRef]

38. Li, R.; Miao, C.; Zhang, M.Q.; Xiao, W. Novel hierarchical structural $\mathrm{SnS}_{2}$ composite supported by biochar carbonized from chewed sugarcane as enhanced anodes for lithium ion batteries. Ionics 2019. [CrossRef]

39. Li, M.W.; Liang, C.P.; Zhang, Y.B.; Yi, Z.; Chen, X.F.; Zhou, Z.G.; Yang, H.; Tang, Y.J.; Yi, Y.G. Terahertz wideband perfect absorber based on open loop with cross nested structure. Results Phys. 2019, 15, 102603. [CrossRef] 
40. Wang, S.; Gao, H.; Chen, C.; Wei, Y.; Zhao, X. Irradiation assisted polyacrylamide gel route for the synthesize of the $\mathrm{Mg}_{1-x} \mathrm{Co}_{x} \mathrm{Al}_{2} \mathrm{O}_{4}$ nano-photocatalysts and its optical and photocatalytic performances. J. Sol Gel Sci. Technol. 2019, 92, 186-199. [CrossRef]

41. Ni, Y.; Xiao, W.; Miao, C.; Xu, M.B.; Wang, C.J. Effect of calcining oxygen pressure gradient on properties of $\mathrm{LiNi}_{0.8} \mathrm{Co}_{0.15} \mathrm{Al}_{0.05} \mathrm{O}_{2}$ cathode materials for lithium ion batteries. Electrochim. Acta 2020, 334, 135654. [CrossRef]

42. Prayakarao, S.; Mendoza, B.; Devine, A.; Kyaw, C.; van Dover, R.B.; Liberman, V.; Noginov, M.A. Tunable $\mathrm{VO}_{2} / \mathrm{Au}$ hyperbolic metamaterial. Appl. Phys. Lett. 2016, 109, 061105. [CrossRef]

43. Liang, C.P.; Zhang, Y.B.; Yi, Z.; Chen, X.F.; Zhou, Z.G.; Yang, H.; Yi, Y.; Tang, Y.J.; Yao, W.T.; Yi, Y.G. A broadband and polarization-independent metamaterial perfect absorber with monolayer $\mathrm{Cr}$ and $\mathrm{Ti}$ elliptical disks array. Results Phys. 2019, 15, 102635. [CrossRef]

44. Wang, S.; Gao, H.; Sun, G.; Li, Y.; Wang, Y.; Liu, H.; Chen, C.; Yang, L. Structure characterization, optical and photoluminescence properties of scheelite-type $\mathrm{CaWO}_{4}$ nanophosphors: Effects of calcination temperature and carbon skeleton. Opt. Mater. 2020, 99, 109562. [CrossRef]

45. Wu, H.; Jile, H.; Chen, Z.Q.; Xu, D.Y.; Yi, Z.; Chen, X.F.; Chen, J.; Yao, W.T.; Wu, P.H.; Yi, Y.G. Fabrication of ZnO@MoS 2 Nanocomposite Heterojunction Arrays and Their Photoelectric Properties. Micromachines 2020, 11, 189. [CrossRef] [PubMed]

46. Zhang, W.B.; Xiao, X.; Wu, Q.F.; Fan, Q.; Chen, S.J.; Yang, W.X.; Zhang, F.C. Facile synthesis of novel Mn-doped $\mathrm{Bi}_{4} \mathrm{O}_{5} \mathrm{Br}_{2}$ for enhanced photocatalytic NO removal activity. J. Alloys Compd. 2020, 826, 154204. [CrossRef]

47. Xian, T.; Di, L.J.; Sun, X.F.; Li, H.Q.; Zhou, Y.J.; Yang, H. Photo-Fenton degradation of AO7 and photocatalytic reduction of $\mathrm{Cr}(\mathrm{VI})$ over $\mathrm{CQD}$-decorated $\mathrm{BiFeO}_{3}$ nanoparticles under visible and NIR light irradiation. Nanoscale Res. Lett. 2019, 14, 397. [CrossRef]

48. Wang, S.; Chen, C.; Li, Y.; Zhang, Q.; Li, Y.; Gao, H. Synergistic Effects of Optical and Photoluminescence Properties, Charge Transfer, and Photocatalytic Activity in $\mathrm{MgAl}_{2} \mathrm{O}_{4}$ : Ce and $\mathrm{Mn}-\mathrm{Codoped} \mathrm{MgAl}_{2} \mathrm{O}_{4}: \mathrm{Ce}$ Phosphors. J. Electron. Mater. 2019, 48, 6675-6685. [CrossRef]

49. Yi, Z.; Zeng, Y.; Wu, H.; Chen, X.F.; Fan, Y.X.; Yang, H.; Tang, Y.J.; Yi, Y.G.; Wang, J.Q.; Wu, P.H. Synthesis, surface properties, crystal structure and dye-sensitized solar cell performance of $\mathrm{TiO}_{2}$ nanotube arrays anodized under different parameters. Results Phys. 2019, 15, 102609. [CrossRef]

50. Yan, Y.X.; Yang, H.; Yi, Z.; Xian, T. $\mathrm{NaBH}_{4}$-reduction induced evolution of Bi nanoparticles from BiOCl nanoplates and construction of promising Bi@BiOCl hybrid photocatalysts. Catalysts 2019, 9, 795. [CrossRef]

51. Meng, W.W.; Lv, J.; Zhang, L.W.; Que, L.C.; Zhou, Y.; Jiang, Y.D. An ultra-broadband and polarization-independent metamaterial absorber with bandwidth of 3.7 THz. Opt. Commun. 2019, 431, 255-260. [CrossRef]

52. Wang, S.; Gao, H.; Wang, Y.; Sun, G.; Zhao, X.; Liu, H.; Chen, C.; Yang, L. Effect of the Sintering Process on the Structure, Colorimetric, Optical and Photoluminescence Properties of $\mathrm{SrWO}_{4}$ Phosphor Powders. J. Electron. Mater. 2020, 49, 2450-2462. [CrossRef]

53. Wang, J.; He, Z.B.; Tan, X.L.; Wang, T.; Liu, L.; He, X.S.; Liu, X.D.; Zhang, L.; Du, K. High-performance $2.6 \mathrm{~V}$ aqueous symmetric supercapacitor based on porous boron doped diamond via regrowth of diamond nanoparticles. Carbon 2020, 160, 71-79. [CrossRef]

54. Wang, S.; Gao, H.; Chen, C.; Li, Q.; Li, C.; Wei, Y.; Fang, L. Effect of phase transition on optical and photoluminescence properties of nano- $\mathrm{MgWO}_{4}$ phosphor prepared by a gamma-ray irradiation assisted polyacrylamide gel method. J. Mater. Sci. Mater. Electron. 2019, 30, 15744-15753. [CrossRef]

55. Wang, H.; Wang, L. Perfect selective metamaterial solar absorbers. Opt. Express 2013, 21, A1078. [CrossRef] [PubMed]

56. Yi, Z.; Li, X.; Wu, H.; Chen, X.F.; Yang, H.; Tang, Y.J.; Yi, Y.; Wang, J.; Wu, P.H. Fabrication of ZnO@ $\mathrm{Ag}_{3} \mathrm{PO}_{4}$ Core-Shell Nanocomposite Arrays as Photoanodes and Their Photoelectric Properties. Nanomaterials 2019, 9 , 1254. [CrossRef] [PubMed]

57. Kearney, B.; Alves, F.; Grbovic, D.; Karunasiri, G. Al/SiOx/Al single and multiband metamaterial absorbers for terahertz sensor applications. Opt. Eng. 2013, 52, 013801. [CrossRef]

58. Cheng, Y.; Nie, Y.; Gong, R. A polarization-insensitive and omnidirectional broadband terahertz metamaterial absorber based on coplanar multi-squares films. Opt. Laser Technol. 2013, 48, 415-421. [CrossRef]

(C) 2020 by the authors. Licensee MDPI, Basel, Switzerland. This article is an open access article distributed under the terms and conditions of the Creative Commons Attribution (CC BY) license (http://creativecommons.org/licenses/by/4.0/). 